\title{
«EL DOCUMENTO DEL MES» DEL ARCHIVO DE INDIAS
}

\section{Texto: Lucía Ballesteros-Aguayo}

El Archivo de Indias, como señala su propia web, aunque era la antigua puerta de entrada del comercio con América, en la actualidad es el testigo de la relación de España con el Nuevo Mundo y lugar de concentración de la amplísima documentación referida a las colonias españolas en Hispanoamérica, que se hallaba dispersa en los archivos de Simancas, Cádiz y Sevilla. Testimonio de un núcleo de riqueza patrimonial histórica y artística incalculable desde que se construyera allá por el siglo XVIII, durante el reinado de Carlos III, quien, pese a que era natural de Madrid, llevó una intensa actividad gobernante desde Sevilla.

Desde su origen, la construcción del Archivo de Indias respondía a una realidad de intensa actualidad que partió del espíritu emprendedor de su impulsor, Carlos III. Él fue quien, durante su reinado, impulsó diversas expediciones por el Pacífico y por la Nueva España con el fin de extender su dominio en ultramar.

Hoy día contiene 43.000 legajos, 80 millones de páginas y 8.000 mapas de dibujos que ocuparían más de nueve kilómetros lineales; además, incluye textos autobiográficos de Colón, Magallanes, Núñez de Balboa, Hernán Cortés o Francisco Pizarro. Todo ello lo convierte en el principal depósito documental de la administración española sobre el Nuevo Mundo y Filipinas con información histórica, geográfica y etnológica.

El pasado 2019, con objeto de la conmemoración del $V$ Centenario de la primera vuelta al mundo de Magallanes y Elcano, el Archivo de Indias organizó el Año Magallanes, en el que se insertaba la exposición "El viaje más largo», una amplísima muestra en la que se exhibieron 106 piezas y documentos de distintas partes del mundo. Todo ello unido a la apuesta por una serie de conferencias, exposiciones, charlas, visitas, etcétera, relacionadas con tan magno acontecimiento, de la que se hicieron eco la mayoría de los rotativos españoles, destacándola en titulares; entre otros, Abc, Sevilla Buenas Noticias, la agencia Europa Press, El Correo de Sevilla, o eldiario.es.

Coincidiendo con este aniversario, el Archivo General de Indias inauguró también la sección «El documento del mes», un apartado dedicado a destacar cada mes un documento, exponerlo y así visibilizar la riqueza patrimonial, histórica, artística, geográfica y etnológica que atesora, y que, aun siendo relevante en un aspecto determinado, permanece ignorado para gran parte de la ciudadanía.

\section{ARTÍCULOS EN PRENSA SOBRE EL ANIVERSARIO DE LA PRIMERA VUELTA AL MUNDO DE MAGALLANES Y ELCANO (ORGANIZADO POR EL ARCHIVO DE INDIAS)}

\begin{tabular}{|c|c|}
\hline $\begin{array}{l}\text { Abc Sevilla, 28-06-2019 } \\
\text { Recuperado de https://sevilla. } \\
\text { abc.es/sevilla/sevi-gran-ex } \\
\text { posicion-archivo-indias-re } \\
\text { lanzara-magallanes-sevi } \\
\text { lla-201906280711 noticia. } \\
\text { html }\end{array}$ & $\begin{array}{l}\text { «El Rey prevé asistir a la } \\
\text { inauguración de la muestra } \\
\text { "El viaje más largo", el } 12 \text { de } \\
\text { septiembre. La capital andalu- } \\
\text { za será ese día la sede de la } \\
\text { comisión del V Centenario» }\end{array}$ \\
\hline $\begin{array}{l}\text { Sevilla Buenas Noticias, } \\
\text { 10-09-2019 } \\
\text { Recuperado de https:// } \\
\text { sevillabuenasnoticias.com/ } \\
\underline{\text { los-reyes-inauguran-en-el- }} \\
\underline{\text { archivo-de-indias-la-mues }} \\
\underline{\text { tra-el-viaje-mas-largo-so }} \\
\underline{\text { bre-la-circunnavegacion/ }}\end{array}$ & $\begin{array}{l}\text { "Los Reyes inauguran en el } \\
\text { Archivo de Indias la muestra } \\
\text { "El viaje más largo" sobre la } \\
\text { circunnavegación» }\end{array}$ \\
\hline $\begin{array}{l}\text { Europapress, 09-09-2019 } \\
\text { Recuperado de https://www. } \\
\text { europapress.es/andalucial } \\
\text { sevilla-00357/noticia-reyes- } \\
\text { inauguran- } \\
\text { jueves-archivo-indias-mues } \\
\text { tra-viaje-mas-largo-circunna } \\
\text { vegacion-20190909184914. } \\
\text { html }\end{array}$ & $\begin{array}{l}\text { "Los Reyes inauguran el } \\
\text { jueves en el Archivo de Indias } \\
\text { la muestra "El viaje más largo" } \\
\text { sobre la circunnavegación» }\end{array}$ \\
\hline $\begin{array}{l}\text { El Correo de Sevilla, } \\
12-09-2019 \\
\text { Recuperado de https:// } \\
\text { elcorreoweb.es/sevilla/los- } \\
\text { reyes-inauguran-la-mues } \\
\text { tra-mas-ambiciosa-sobre-la- } \\
\text { primera-vuelta-al-mundo- } \\
\text { JE5789281 }\end{array}$ & $\begin{array}{l}\text { "Los Reyes inauguran la } \\
\text { muestra más ambiciosa sobre } \\
\text { la primera vuelta al mundo» }\end{array}$ \\
\hline $\begin{array}{l}\text { eldiario.es 12-09-2019 } \\
\text { Recuperado de https://www. } \\
\text { eldiario.es/politica/inaugu } \\
\text { ran-principal-muestra-Maga } \\
\text { Ilanes-Elcano } 0941406584 . \\
\text { html }\end{array}$ & $\begin{array}{l}\text { «Los reyes inauguran la prin- } \\
\text { cipal muestra de la epopeya } \\
\text { de Magallanes y Elcano» } \\
\text { "Sevilla exhibe por primera } \\
\text { vez documentos del viaje de } \\
\text { Magallanes y Elcano» }\end{array}$ \\
\hline
\end{tabular}

Fuente: elaboración propia. 
Hasta donde abarca nuestra investigación, en total son ocho los documentos publicados en la web oficial del Archivo General de Indias desde que se inauguró esta sección, que se corresponden cronológicamente con los meses de octubre, noviembre y diciembre de 2019, y enero, febrero, marzo, abrily mayo de 2020. Nosotros nos aproximaremos a analizarlos guiados de los archiveros técnicos y de los analistas, quienes nos ofrecen una recreación interesante y atractiva de cada uno de ellos mostrándonos la grandeza de la tradición archivística.

\section{El documento de octubre de 2019: EI IV Centenario del 12 de octubre en la prensa española del siglo XIX}

La inauguración en 2019 de la sección «El documento del mes» del Archivo de Indias coincide con una efeméride muy significativa: la conmemoración del IV Centenario del Descubrimiento de América por Cristóbal Colón. Esta conmemoración constituyó un acontecimiento histórico relevante que no pasó inadvertido en ningún rincón de la España peninsular y que la prensa del momento supo recrear en todo su esplendor.

La prensa, junto con la historia, son testigos fieles de los acontecimientos contados a través de sus relatores, los periodistas y los historiadores. Es por ello por lo que este primer documento del mes de octubre de 2019 está referido a un volumen monográfico que el periódico El Liberal de Madrid dedica el 12 de octubre de 1892 a este acontecimiento. El Liberal fue uno de los periódicos más representativos por su tirada nacional y, además, no tener adscripción política pudiera ser que aumentara su valor testifical de la narrativa de los acontecimientos.

La archivera Reyes Rojas García, técnico superior de Archivos, señala que pertenece al archivo de la familia Rivero Solesio, depositado en el Archivo General de Indias.

Destaca también que su conservación es reveladora de las operaciones llevadas a cabo a favor de la independencia de las tierras conquistadas y así lo afirma Rojas (2019): «Este ejemplar, dedicado a la empresa colombina, nos da la oportunidad de conocer la visión que, en los años previos a la independencia de los últimos territorios ultramarinos, se tenía de este hecho y sus consecuencias».

El primer artículo del diario lo firma el dramaturgo madrileño José Echegaray y lo dedica a destacar la figura de Cristóbal Colón, de quien subraya la valentía y empuje del personaje para adentrarse en gestas importantes, novedosas y aventureras. Según recoge Rojas (2019), Echegaray resalta «la capacidad que tenían [Cristóbal Colón y sus contemporáneos] de "mirar hacia delante; ver un mar sin límites que se pierde en un horizonte misterioso, y meterse mar adentro hacia lo desconocido"».

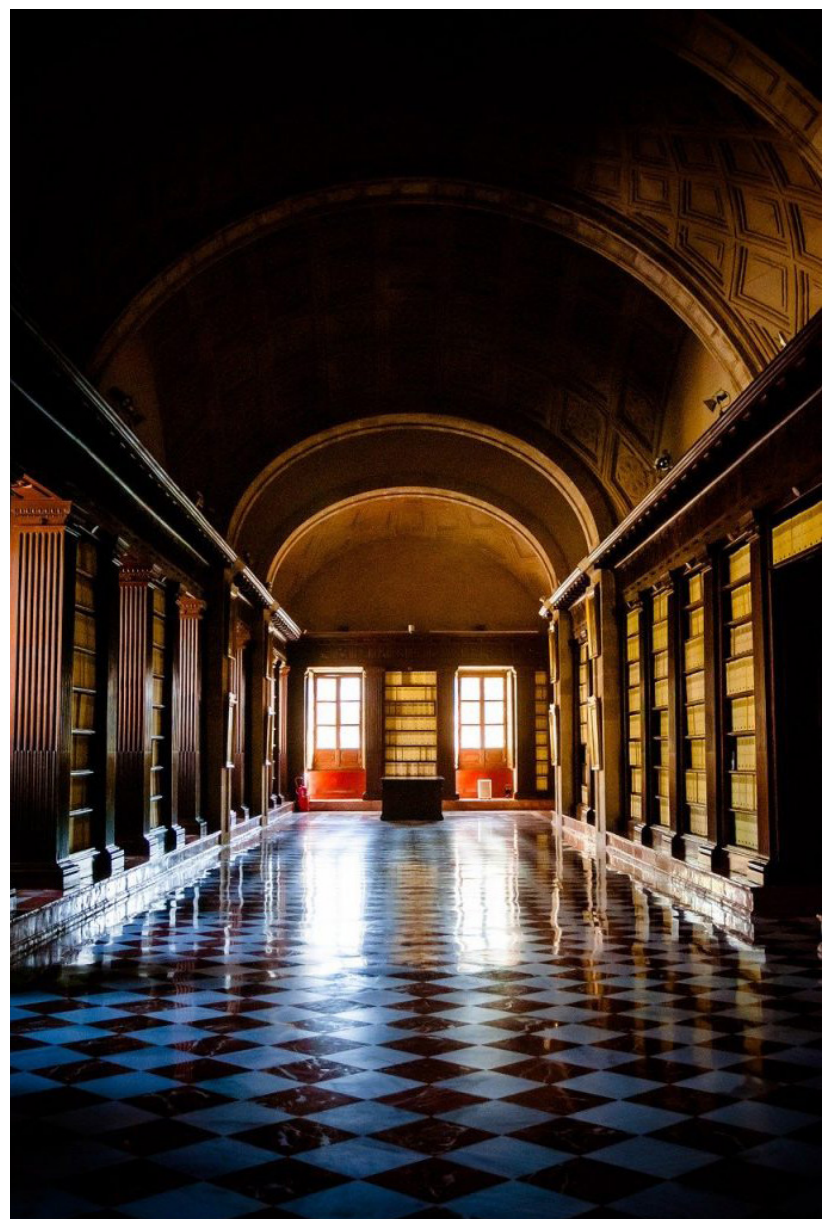

El interior del Archivo de Indias reúne documentación sobre las colonias españolas en el Nuevo Mundo. Fuente: https://www.shu tterstock.com/es/search/archivo+de+indias+sevilla

Rojas, asimismo, acentúa la calidad de articulistas como Castelar o Menéndez Pelayo, columnistas como Isidoro Fernández Flores («Fernanflor»), poetas como Zorrilla o historiadores como Pi y Margall, personajes todos ellos sin duda influyentes en la época que el periódico aglutinaba en torno a sus páginas logrando convertirse en un referente de la prensa de la época. De este modo describe Reyes Rojas (2019) la gran influencia que ejerció El Liberal:

El ejemplar que presentamos pertenece al diario El Liberal, fechado el miércoles, 12 de octubre de 1892. Este diario, que se define como republicano liberal pero moderado y sin adscripción a ningún partido político, se empieza a publicar en 1879 y va a gozar de una importante influencia, sobre todo entre la clase obrera, llegando a ser uno de los diarios de mayor tirada del panorama periodístico español a comienzos del siglo XX. Su último número se publica el 28 de marzo de 1939, al ser incautado por el gobierno franquista. 
La archivera señala también la importancia de este volumen más allá del ámbito peninsular, pues recoge los discursos de alcaldes de ultramar, presidentes de distintas repúblicas americanas y otros en relación con la conquista y las relaciones tan estrechas que se llevaron a cabo entre las dos Españas.

\section{El documento de noviembre de 2019: El parecer de don Hernando Colón}

Siguiendo con el objetivo de visibilizar documentos y personajes poco reconocidos por gran parte de la ciudadanía, el documento del mes de noviembre se refiere al personaje Hernando de Colón. Desconocido, pero influyente, este español renacentista a quien el Archivo de Indias dedica un especial reconocimiento destaca por los logros que consigue en dos disciplinas distintas reflejadas en dos interesantes cartas, ambas de un valor exquisito tanto por la relevancia de sus aportaciones como por el carácter científico técnico del personaje.

Una de ellas dedicada a la astronomía y otra al derecho, dos actividades que, sin duda, eran de suma importancia en plena expansión colonial. Una para asegurar el éxito de las expediciones, mejorar las rutas de navegación y conseguir óptimos resultados; la otra para garantizar la administración, gobierno y justicia de los territorios conquistados, donde Hernando de Colón se aproxima a lo que con Francisco de Vitoria se llamará derecho internacional o derecho de gentes.

En ambas cartas nos adentramos de la mano del archivero Guillermo J. Morán Dauchez, del Cuerpo Facultativo de Archiveros del Estado, quien describe los hallazgos del personaje en astronomía del siguiente modo: «En la primera de ellas, fechada en Badajoz el 13 de abril de 1524, se explica con precisión el problema geográfico más acuciante de su época: la imposibilidad de medir de forma precisa la longitud geográfica».

Morán (2019) afirma que esto justifica los múltiples esfuerzos que los cosmógrafos del momento dedicaron a ingeniar métodos de observación astronómica que permitieran la determinación de la diferencia de longitud entre dos puntos, los cuales enumera y explica con brevedad y precisión Hernando Colón: «Pero como esta forma de medir los grados, aunque de septentrión en austro es fácil, de oriente en occidente sea difícil, será necesario recurrir a algunas exquisitas y sutiles maneras de las cuales, aunque tengan todos entera noticia, no dejaré de decir algunas que he podido alcanzar por dar ocasión que estos señores manifiesten las que yo ignoro».

Hernando Colón, después de ofrecer distintas soluciones, culmina proponiendo una especie de cronógrafo con la hora local para compararla con la solar y así dar cuenta de las diferencias horarias. Este reloj, aunque más tarde se perfeccionara, fue una clara anticipación a esa medición, la primera que se conserva en la historia.

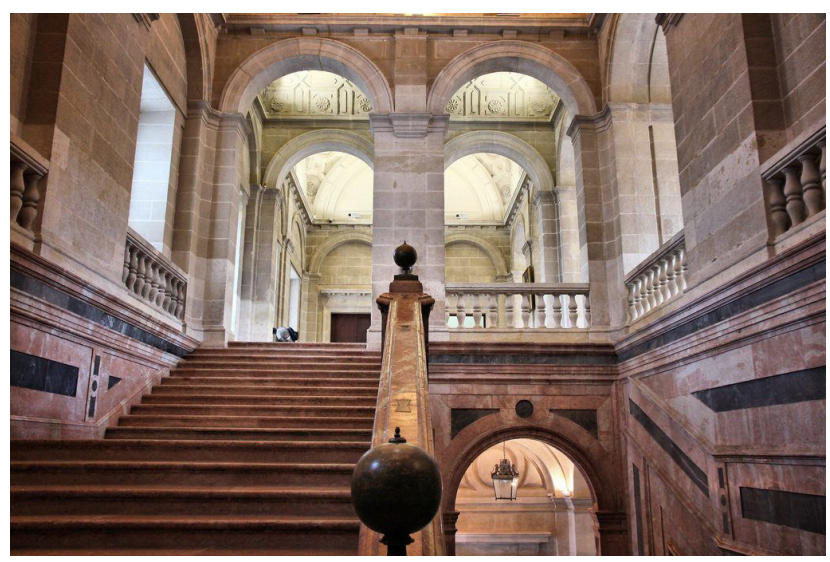

El edificio que alberga el actual archivo se construyó durante el reinado de Carlos III. Fuente: https://www.shutterstock.com/es/ search/archivo+de+indias+sevilla

La segunda carta está en estrecha relación con la primera y, como hemos señalado más arriba, ligada también al proceso de colonización, pues, en el marco del derecho internacional, Hernando Colón describe una forma de argumentar de forma negativa novedosa acerca de los derechos de los reyes de Castilla en relación a las islas Molucas. Esta cuestión se mantiene candente durante toda la época, especialmente después del regreso de Juan Sebastián Elcano a Sevilla, como nos recuerda Morán (2019):

\begin{abstract}
Resta, finalmente, la segunda de las cartas mencionadas fechada tres días después, en que Hernando, ante lo insuficiente del conocimiento científico de la época para resolver el problema de la partición, ofrece las directrices de la estrategia negociadora que, según él, habría de seguirse: no cabe discutir si Portugal ha excedido los límites de Tordesillas, puesto que ello no se puede probar definitivamente, sino mantener que Castilla ha obrado conforme al tratado, dejando recaer sobre la otra parte la tarea de probar falso tal argumento «y como la prueba sea difícil, su majestad será justo poseedor en tanto que lo averiguan [...], pues es manifiesto que, quien algo ha de probar, es por falta de claridad de su justicia».
\end{abstract}

\section{El documento de diciembre de 2019: \\ Relaciones de regalos hechos en Navidad en azúcar, chocolates y dinero}

El documento del mes de diciembre hace referencia al origen de lo que pudiera significar la costumbre 
de nuestra actual paga extra de Navidad mostrando un documento de 1757 de la Compañía de la Habana. En él se describe una relación de regalos en forma de azúcares, chocolates u otras dádivas que la Compañía de la Habana acostumbraba a regalar a oficiales y miembros ministeriales, poniéndose de manifiesto la conveniencia o no de hacerlo por el gasto que suponía.

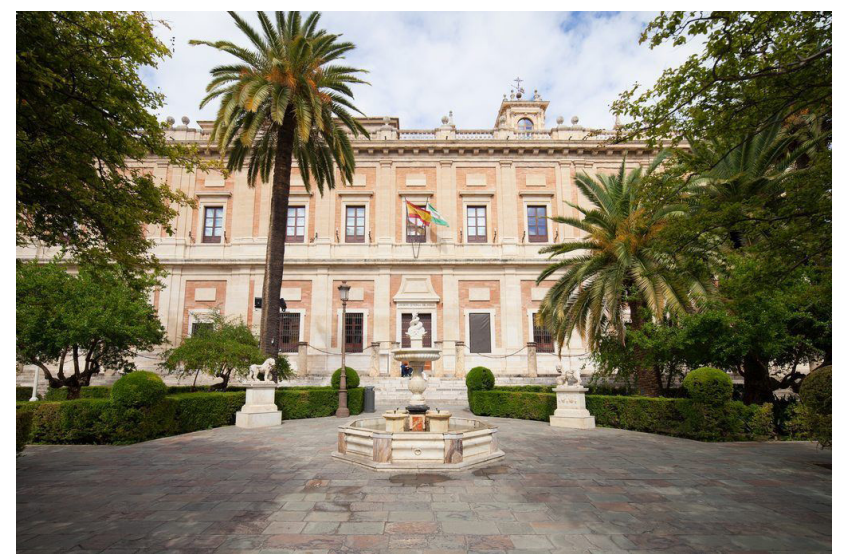

Exterior del Archivo de Indias. Fuente: https://www.shutterstock. com/es/search/archivo+de+indias+sevilla

Marta Velasco Contreras, técnico superior de Archivos, realiza un interesante recorrido histórico en el que remonta la palabra «aguinaldo»-homóloga de la paga extra- posiblemente a un pasado celta en el que la palabra eguinad se refería a las necesarias ofrendas a los dioses con objeto de recibir buenas cosechas. Ello se prolongó durante muchas generaciones hasta llegar a nuestros días como la paga extra de Navidad.

De cualquier modo, es una tradición extendida en toda la geografía española que se originó ligada a los dulces y el azúcar, los mazapanes, los chocolates y productos en buena medida importados desde ultramar, por lo que adquiere un protagonismo especial la Compañía de la Habana en lo que a nuestro estudio se refiere. En palabras de Velasco (2019):

La Compañía de la Habana, importadora de azúcar, se fundó el 18 de diciembre de 1740 por una real cédula en la que Felipe $V$ estableció su organización y funcionamiento y fijó su sede en La Habana, con personal en la Corte, el Consejo y en Sevilla, Coruña, Cádiz y San Sebastián. Su fundación, como una empresa mercantil por acciones, se debió al impulso de la iniciativa privada, y los resultados que obtuvo fueron indiscutibles.

Así, la Compañía de la Habana emprendió una intensa actividad comercial favorecida por la situación geográfica estratégica de Cuba, lugar de paso obligado, de manera que se hizo principalmente con el monopolio del azúcar, del chocolate y de otros productos usados en la gastronomía como bienes exóticos o inusuales, pero imprescindibles en las grandes celebraciones como son las fiestas navideñas.

\section{El documento de enero de 2020: La muerte del grumete Guillermo}

Es muy interesante el documento del mes de enero, del que se infiere una visión sociohistórica de los expedicionarios de las conquistas. Concretamente, nos permite visibilizar con mayor exactitud la estructura social jerarquizada en las expediciones. De hecho, el documento del mes del Archivo General de Indias que analiza Braulio Vázquez relata la muerte del grumete Guillermo en la expedición de Fernando de Magallanes apoyándose en tres documentos.

Así da cuenta Vázquez (2020):

De aquel grumete no conocemos apenas más que su nombre, Guillermo o Guillén, igual que su padre, y que era natural de "Galbay» (¿Galway, en Irlanda?). Así nos lo cuentan la relación de tripulantes (Archivo General de Indias, Patronato Real, 34, R. 6) y el listado de fallecidos de aquella expedición (Archivo General de Indias, Patronato Real, 34, R. 11), así como la información sobre los sueldos que se les debían a los participantes (Archivo General de Indias, 425, N. 1, R. 1).

La estructura jerárquica de los componentes de la Armada a las islas de las Especias se establecía con frecuencia en razón de la edad de sus miembros, de modo que a los de menor edad se les encomendaba labores degradantes, se les pagaba mucho menos, recibían trato vejatorio y realmente aparecían como innombrables.

En la descripción que destaca Vázquez (2020), los miembros que constituían las expediciones se encuentran escalonados formando una pirámide estricta que iba desde los personajes importantes a los pajes, pasando por los grumetes. El lugar ocupado en esa pirámide era fundamental para su consideración social, para la asignación de tareas y para ajustar el sueldo que debía percibir: «Los grumetes solían ser adolescentes que aprendían de los marineros el oficio, normalmente haciéndose cargo de las tareas físicamente más exigentes. En esta armada un grumete como Guillermo cobraba 800 maravedís mensuales frente a los 1.200 que cobraba un marinero adulto». 


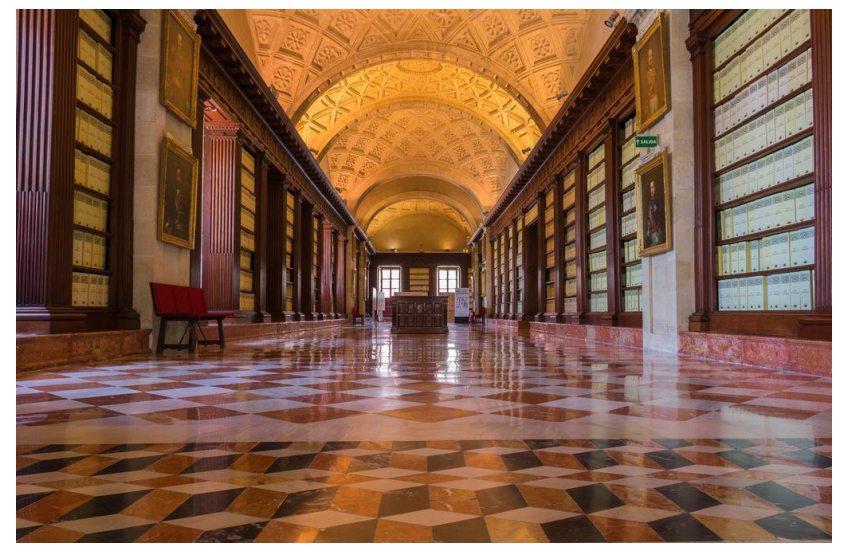

El Archivo de Indias es el principal depósito documental sobre las colonias americanas y filipinas del imperio español. Fuente: https://www.shutterstock.com/es/search/archivo+de+indias+se-

\section{El documento de febrero de 2020: Káin Ná!}

El documento del mes de febrero se refiere a un interesante libro de recetas titulado La cocina filipina. Colección de fórmulas prácticas y posibles en Filipinas para comer bien, del que hace la reseña Antonio Sánchez de Mora, del Archivo General de Indias. El archivero destaca el carácter anónimo de la obra publicada en 1913 en Manila, de la que el Archivo de Indias cuenta con uno de los dos ejemplares que se han localizado (el otro está en Manila). En él se recoge la gastronomía típica filipina. Sánchez de Mora (2020) lo relata así:

\begin{abstract}
La imprenta Pinpin, ubicada en el distrito manileño de Santa Cruz, hizo una tirada reducida, de la que apenas se han localizado dos ejemplares, uno en la Rizal Library del Ateneo de Manila y otro en el Archivo General de Indias de Sevilla. Además, se da la circunstancia de que el ejemplar hispalense cuenta con una historia añadida: fue adquirido en su tierra de origen al precio de 1 peso filipino, traído a España en fecha incierta y donado al Archivo General de Indias por uno de sus oficiales, Eduardo Sánchez-Arjona, el 29 de noviembre de 1918.
\end{abstract}

Su estilo y los ingredientes que describe hacen suponer que el autor es español y que se podría tratar de un gaditano afincado en Filipinas, por su similitud con las costumbres de Cádiz y por las importantes relaciones comerciales del puerto marítimo gaditano, que permitían un trasvase de influencias intenso de las colonias a la península.

Sánchez de Mora señala que las recetas que recoge el libro se asemejan mucho a las españolas y abundan los potajes, salchichones, arroz a la valenciana, etcétera, lo que permite la verosimilitud de atribuir la autoría a un español. Al mismo tiempo, Sánchez de Mora (2020) relaciona el recetario con el libro Káin Ná!, al que considera complementario:
El libro Káin Ná!. Let's Eat: An Illustrated Guide to Philippine Food, de Felice Prudente Sta. Maria y Bryan Koh, difunde de forma amena la riqueza gastronómica de este archipiélago, acompañando los textos de sugerentes ilustraciones de Mariel Ylagan Garcia. Se trata de una visión actual y divulgativa de la cocina filipina, que se complementa a la perfección con una obra muy singular, conservada en el Archivo General de Indias desde hace algo más de un siglo.

\section{El documento de marzo de 2020: Más que monja, alférez}

En esta ocasión el documento del mes de marzo se refiere a la autobiografía de una de las mujeres del siglo XVII español, Catalina de Erauso, nacida en San Sebastián alrededor de 1592. En él se relatan las difíciles relaciones identitarias de género en la sociedad androcéntrica colonial de la época.

No debió ser especialmente fácil sobrevivir en un mundo en el que la mujer tenía por regla general una presencia secundaria y mucho menos si consideramos que su presentación como alférez supone un añadido de dificultad en razón de su sexo.

Aunque resulta confusa la fecha de su nacimiento, según señala Javier Vélez Escofet, jefe de Sección de Archivos del Archivo General de Indias, se sabe que nació en San Sebastián en una familia «asentada y relacionada» y que viajó por España en «ábito de barón» y se instaló en Perú. Su biografía la recoge Vélez (2020):

Publicada en París tan tarde como en la década de los veinte del siglo XIX, La historia de la Monja Alférez, escrita por ella misma es un relato extraordinariamente vívido, en el que la propia protagonista nos hace relación de sus vivencias, al parecer con plena consciencia de su excepcionalidad.

Como muchas mujeres en la historia que se presentaron como hombres -recordemos, por ejemplo, que George Sand era la francesa Amantine Dupin, pero firmaba con un pseudónimo de varón para que publicaran su obra-, también Catalina «se refiere a sí misma en masculino» en una sociedad indiana posiblemente hostil a que destacara una mujer.

Pero lo que es verdaderamente excepcional y no deja de sorprendernos es que esta monja aparezca en varios documentos del Archivo de Indias solicitando una pensión a la corona por los servicios prestados como alférez durante quince años. Así lo manifiesta Vélez (2020) en el documento que destacamos:

Catalina afirma haber empleado 15 años [...] en servicio de V. Magestad en las guerras del Reyno 
de Chile y las yndias del Pirú habiendo passado a aquellas partes en avito de barón por particular ynclinación que tuvo de exercitar las armas en defensa de la fee católica y emplearsse en servicio de V. Magestad [...] recibiendo particularmente heridas en la batalla de Purén por lo que pide [...] por la singularidad y prodigio que biene a tener su discurso teniendo atención en que es hija de padres nobles hidalgos [...] que se le dé un entretenimiento de setenta pesos de a veintidós quilates al mes.

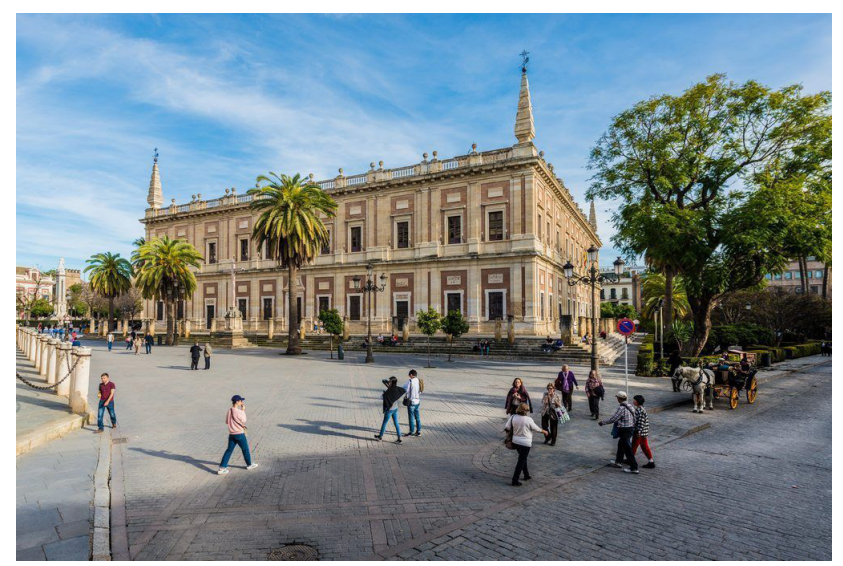

Desde el 2019, el Archivo de Indias da a conocer «El documento del mes» con el objetivo de visibilizar tanto personajes como hechos históricos poco conocidos por el público general. Fuente: https://www. shutterstock.com/es/search/archivo+de+indias+ sevilla

\section{El documento de abril de 2020: Los niños vacuníferos de la Real Expedición Filantrópica de la Vacuna (1803-1810)}

El documento del mes de abril está de rigurosa actualidad y pretende ser un homenaje a las investigaciones que se están llevando a cabo hoy día en distintos laboratorios e instituciones españolas en relación con la intensa búsqueda de la vacuna contra el COVID-19. De manera que recoge la real expedición filantrópica que llevó a cabo el médico Francisco Javier de Balmis con ocasión de llevar la vacuna de la viruela a las colonias españolas.

El documento que se cita es un "Grabado representando un niño, con un perrito e instrumentos musicales, ilustrando las zonas de aplicación de la vacuna de la viruela, la lanceta con la que se realizaba dicha aplicación y tres botones que muestran la evolución de tamaño y aspecto, desde el $4^{\circ}$ al $11^{\circ}$ día».

La enfermedad de la viruela -según nos indica Falia González Díaz, del Archivo General de Indias-, que el continente europeo exportó a ultramar, llegó a arruinar a los pueblos indígenas creando una gran epidemia por ambos continentes. De manera que se convirtió en la primera epidemia realmente virulenta que afectó incluso a la Casa Real, de ahí la necesidad de las vacunaciones masivas, particularmente a los niños, que tenían más capacidad de respuesta inmunológica.

Aunque fueron varias las propuestas que le presentaron a Carlos IV para enviar expediciones vacunatorias a los territorios conquistados por la gran expansión de la viruela en ultramar, fue justamente la del médico Balmis la que finalmente se aprobó. Así lo describe González Díaz, quien relata de este modo la aprobación de la expedición:

\begin{abstract}
Fue Francisco Javier de Balmis, también médico de cámara de Carlos IV, que había traducido el Tratado histórico y práctico de la vacuna de Jacques-Louis Moreau de la Sarthe, divulgador de la obra de Jenner en Europa y que incluso mantenía en Madrid una consulta gratuita de vacunación. Balmis presentó al rey un proyecto diferente al de Flores que fue aprobado por la Junta de Cirujanos de Cámara el 23 junio de 1803 y ratificado por el rey el día 28, siendo designado como director de la expedición. Como subdirector fue nombrado José Salvany y Lleopart. La integraban también médicos ayudantes, practicantes, enfermeros y los más importantes, los sujetos que portarían la vacuna, los niños vacuníferos pues esta había sido la única propuesta que presentó Balmis para transportar la vacuna. Iban a cargo de la única mujer de la expedición: Isabel Zendal, madre de uno de ellos, y que actuaba también como enfermera.
\end{abstract}

Finalmente, «la Real Expedición Filantrópica de la Vacuna partió de A Coruña con destino a América el 30 de noviembre de 1803" y se calcula que se vacunaron 300.000 personas. La expedición se encargó también de ejercer una pedagogía adecuada entre la población para evitar nuevos contagios.

\section{El documento de mayo de 2020: ¡Queda la música!}

El proceso de evangelización de las colonias provocó estrechos lazos eclesiales con los territorios colonizados. Resultado de ello es la rica mezcolanza armónica de diversos cantos litúrgicos que se amalgama en sinfonías multiformes en las que se mezclan ritmos indígenas con la música llevada por los evangelizadores.

El documento del mes de mayo es múltiple, porque pretende recoger las composiciones musicales de diferentes clérigos españoles que decidieron irse a América para ejercer su labor evangelizadora a través de la música, como Cristóbal Ximénez de Carpio en La Plata o el profesor gaditano Miguel de Gomara en Veracruz.

La técnico superior de archivos del Archivo General de Indias Reyes Rojas García será quien nos describa el resultado de la música seleccionada: 
Los primeros documentos los dedicamos a los profesionales que decidieron emprender la aventura de irse a América a ejercer su oficio, como Cristóbal Ximénez del Carpio, clérigo presbítero y maestro de canto en La Plata desde, al menos, 1560.

El documento señala que Cristóbal Ximénez «era buen conocedor de la lengua indígena y "por tener tan buena voz como tiene de contralto es tan famoso cantor e aventaxado ansí en el canto de órgano como en el canto llano"».

La música es el lenguaje universal que une pueblos y traspasa fronteras, permite confraternizar fácilmente con nuestros semejantes y cohesiona a la sociedad como pueblo universal, de ahí que merezca un reconocimiento especial en este archivo.

\section{Fuentes ybibliografía}

Archivo de Indias (2019): El documento del mes. Recuperado de http://www.culturaydeporte.gob.es/cultural areas/archivos/mc/archivos/agi/exposiciones-y-activi dades/documento-del-mes.html

González Díaz, J. (2020), abril: Los niños vacuníferos de la Real expedición Filantrópica de la Vacuna (1803-1810). Recuperado de http://www.culturaydeporte.gob.es/ dam/jcr:5a2d4aec-45e0-4088-a2d4-52e550a32ec0/ documento-mes-agi-abril-2020-compressed.pdf
Morán Dauchez, G. J. (2019): El parecer de don Hernando Colón. Recuperado de http://www.culturaydeporte.gob.es/dam/jcr:4849bc84-3167-48cc-968d-9b21c 17943fa/2019-noviembre-documento-del-mes-r.pdf

Rojas García, R. (2019): El IV Centenario del 12 octubre en la prensa española del siglo XIX, octubre. Recuperado de http://www.culturaydeporte.gob.es/ dam/jcr:f494139e-5f36-41d1-9133-34fba42fcad8/ el\%20iv\%20centenario\%20del\%2012\%20de\%20octu bre\%20en\%20la\%20prensa\%20espa\%C3\%B1ola4. pdf

-(2020): ¡Queda la música!, mayo Recuperado de http:// www.culturaydeporte.gob.es/dam/jcr:bd5074ed-e 158-4893-bfbd-1df117ff0c60/agi-documentomes-mayo-.pdf

Sánchez de Mora, A. (2020): Káin Ná!, febrero. Recuperado de http://www.culturaydeporte.gob.es/dam/jcr:be cb8425-7d98-4418-8b99-824d293c9bf2/documen to-mes-febrero2020.pdf

Vázquez, B. (2020): La muerte del grumete Guillermo, enero. Recuperado de http://www.culturaydeporte. gob.es/dam/jcr:f114b032-e392-4e6e-8768-cea8a9f60ac7/documento-mes-enero2020.pdf

Velasco Contreras, M. (2019): Relaciones de regalos hechos en Navidad en azúcar, chocolates y dinero, diciembre. Recuperado de http://www.culturaydeporte. gob.es/dam/jcr:22feaa24-37b0-4630-94bb-8da200e0a69f/documento-mes-diciembre-2019.pdf

Vélez Escofet, J. (2020): Más que monja, alférez, marzo. Recuperado de http://www.culturaydeporte.gob.es/ dam/jcr:eb4238cc-52eb-4de6-ae75-d90d3214cb67/ doumento-marzo2020-la-monja-alf-rez.pdf 